University of Nebraska - Lincoln

DigitalCommons@University of Nebraska - Lincoln

\title{
Microstructure and mechanical properties at different length scales and strain rates of nanocrystalline tantalum produced by high-pressure torsion
}

Q. Wei

University of North Carolina at Charlotte, qwei@uncc.edu

Z. L. Pan

University of North Carolina at Charlotte

X. L. Wu

The Chinese Academy of Sciences

B. E. Schuster

US Army Research Laboratory

L. J. Kecdkes

US Army Research Laboratory

See next page for additional authors

Follow this and additional works at: https://digitalcommons.unl.edu/usarmyresearch

Part of the Operations Research, Systems Engineering and Industrial Engineering Commons

Wei, Q.; Pan, Z. L.; Wu, X. L.; Schuster, B. E.; Kecdkes, L. J.; and Valiev, R. Z., "Microstructure and mechanical properties at different length scales and strain rates of nanocrystalline tantalum produced by high-pressure torsion" (2011). US Army Research. 159.

https://digitalcommons.unl.edu/usarmyresearch/159

This Article is brought to you for free and open access by the U.S. Department of Defense at DigitalCommons@University of Nebraska - Lincoln. It has been accepted for inclusion in US Army Research by an authorized administrator of DigitalCommons@University of Nebraska - Lincoln. 


\section{Authors}

Q. Wei, Z. L. Pan, X. L. Wu, B. E. Schuster, L. J. Kecdkes, and R. Z. Valiev 


\title{
Microstructure and mechanical properties at different length scales and strain rates of nanocrystalline tantalum produced by high-pressure torsion
}

\author{
Q. Wei ${ }^{\mathrm{a}, *}$, Z.L. Pan ${ }^{\mathrm{a}}$, X.L. Wu ${ }^{\mathrm{b}}$, B.E. Schuster ${ }^{\text {c }}$, L.J. Kecskes ${ }^{\mathrm{c}}$, R.Z. Valiev ${ }^{\mathrm{d}}$ \\ ${ }^{a}$ Department of Mechanical Engineering and Engineering Science, University of North Carolina at Charlotte, 9201 University City \\ Blvd., Charlotte, NC 28223-0001, USA \\ ${ }^{\mathrm{b}}$ State Key Laboratory of Non-Linear Mechanics, The Institute of Mechanics, The Chinese Academy of Sciences, Beijing 100190, People's Republic of China \\ ${ }^{\mathrm{c}}$ US Army Research Laboratory, Aberdeen Proving Ground, Aberdeen, MD 21005, USA \\ ${ }^{\mathrm{d}}$ Institute of Physics of Advanced Materials, Ufa State Aviation Technological University, Ufa 450000, Russia
}

Received 9 December 2010; received in revised form 20 December 2010; accepted 21 December 2010

Available online 25 January 2011

\begin{abstract}
Fully dense, nanocrystalline tantalum (average grain size as small as $\sim 40 \mathrm{~nm}$ ) has been processed for the first time by high-pressure torsion. High-resolution transmission electron microscopy reveals non-equilibrium grain boundaries and grains decorated with high-density dislocations. Microhardness measurements and instrumented nanoindentation experiments indicate that the mechanical property is quite uniform except for the central area of the disks. Nanoindentation experiments at different strain rates suggest that the strain rate sensitivity of nanocrystalline tantalum is increased compared to the coarse- and ultrafine-grained counterparts and is accompanied by an activation energy of the order of a few $\sim b^{3}$ ( $b$ is the magnitude of the dislocation Burgers vector), implying a shift in the plastic deformation mechanism from the screw dislocation dominated regime. We thus infer the plastic deformation mechanisms of nanocrystalline body-centered cubic (bcc) and face-centered cubic metals converge. To examine the stress-strain behavior, we have used microcompression to measure the compressive stress-strain curves on microscale pillars fabricated by focused ion beam technique. Yield strength as high as 1.6 GPa has been observed. High-strain rate behavior has been investigated using a miniature Kolsky bar system. We have found that at high-strain rates the nanocrystalline tantalum specimens exhibit adiabatic shear banding, a dynamic plastic deformation mode common to many ultrafine-grained and all nanocrystalline bec metals.
\end{abstract}

(C) 2010 Acta Materialia Inc. Published by Elsevier Ltd. All rights reserved.

Keywords: Nanocrystalline; Tantalum; Microstructure; Mechanical properties; Adiabatic shear band

\section{Introduction}

The processing and characterization of various nanocrystalline materials have drawn great attention from both academic researchers and industry [1,2]. Among the nanocrystalline materials, nanocrystalline metals have created tremendous interest among materials science and engineering community. It has been commonly accepted that if the average grain size of a polycrystalline metal is below

\footnotetext{
* Corresponding author. Tel.: +1 7046878213 ; fax: +1 7046878345.

E-mail address: qwei@uncc.edu (Q. Wei).
}

$100 \mathrm{~nm}$, the metal is called nanocrystalline. Even though it has long been recognized by metallurgists that grain size imparts a strong influence on the mechanical properties of metals $[3,4]$ and much effort has been exercised to investigate the effect of grain size on other properties of metals, great interest in nanocrystalline metals has been witnessed for almost two decades. This is primarily due to the discovery of certain new phenomena as the grain size is refined into the real nanoregime. One important example is the inverse Hall-Petch relation whereby below some critical grain size, as the grain size is further reduced, the strength levels off or even starts to decrease [5-10]. This inverse 
Hall-Petch effect has been corroborated by both experiments and atomistic simulations $[7,11,12]$.

A survey of the literature indicates that the vast majority of investigations into the processing, microstructure and mechanical properties of nanocrystalline metals in the past two decades have concentrated on metals with face-centered cubic (fcc) structures [13-15]. Among such metals, copper, nickel and aluminum have been the most extensively studied [16-35]. For those fcc metals, a grain size as small as $10 \mathrm{~nm}$ can be produced by various techniques. In contrast, far fewer studies can be found in the literature on the processing, microstructure and mechanical properties of nanocrystalline metals with body-centered cubic (bcc) structures. The existing articles on bcc metals concern metals produced by powder metallurgy, which unavoidably results in materials with poor quality, viz. poor inter-particle bonding, porosity and contamination, which consequently render interpretation of the experimental results complex [36].

In this work, we used high-pressure torsion (HPT) to produce nanocrystalline tantalum with a grain size far below the upper bound of the nanoregime. We have characterized the microstructures of the processed tantalum, and investigated the mechanical properties of the material at different length scales and strain rates.

\section{Experimental}

\subsection{High-pressure torsion}

The principles and technical details of HPT can be found in the comprehensive review by Zhilyaev and Langdon [37]. Briefly, a disk of commercial purity tantalum (Stark) with $1.2 \mathrm{~mm}$ thickness and $10 \mathrm{~mm}$ diameter was subjected to a pressure of $\sim 5.0 \mathrm{GPa}$. Five rotations were imposed to the disk-shaped tantalum billet at room temperature. The following equation can be used to estimate the von Mises equivalent strain $\left(\varepsilon_{V M}\right)$ exerted on the billet:

$\varepsilon_{V M}=\frac{2 \pi N \cdot r}{\sqrt{3} \cdot h}$

where $N$ is the number of rotations, $r$ is the distance from the center of the disk and $h$ is the thickness of the disk. This equation is valid on the grounds of the following assumption: the disk is under strict confinement and no slippage occurs during HPT between the tantalum disk and the lower support and upper punch. Based on Eq. (1), for example, for the tantalum disks in this work, after five rotations, the maximum von Mises equivalent strain (at the disk edge) is $\sim 90$. Considering the high melting point of tantalum and thus the low homologous temperature corresponding to room temperature, an extraordinarily large amount of plastic strain has been imposed upon the tantalum disk without significant recovery and recrystallization.

\subsection{Microstructural analysis}

The grain size of the HPT-processed tantalum disks was first analyzed using Bruker AXS D8 Discover X-ray dif- fractometer system. The radiation was $\mathrm{Cu} \mathrm{K} \alpha$ $(\lambda=0.154 \mathrm{~nm})$. Samples for transmission electron microscopy were prepared following standard procedure of mechanical polishing, dimpling and ion-milling. The details of the microstructure, including grain size, grain size distribution and grain boundaries, were examined using transmission electron microscopy (JOEL $2010 \mathrm{~F}$, operating at $200 \mathrm{kV}$ ). High-resolution imaging was used to analyze the atomic structure of the grain boundaries of the HPT-processed tantalum.

\subsection{Nanoindentation and microcompression}

The hardness and Young's modulus of the HPT-Ta samples were measured using instrumented nanoindentation (Nano-indenter XP-II). To evaluate the strain rate sensitivity of the samples, nanoindentation was performed at different nominal strain rates $\left(0.2,0.4\right.$ and $0.8 \mathrm{~s}^{-1}$, respectively). The strain rate sensitivity $(m)$ was derived using the following equation [38]:

$m=\frac{\partial \ln H}{\partial \ln \dot{\epsilon}}$

where $H$ is the hardness and $\dot{\epsilon}$ is the imposed nominal strain rate. In addition, the relation between the strain rate sensitivity and the activation volume associated with plastic deformation of the material is given as [38]

$m=3 \sqrt{3} \frac{k T}{H \cdot v^{*}}$

From Eq. (3) the activation volume $v^{*}$ can be calculated based on the experimentally derived $m$.

Due to the limited specimen size, it is challenging to measure the stress-strain behavior of the HPT nanocrystalline Ta $[39,40]$. In view of this, we used microcompression to probe the quasi-static stress-strain behaviors of specimens located at different positions of the HPT disk. Since the pioneer work by Uchic and co-workers [41] using microcompression to probe the mechanical properties of small samples and to explore the size effect of various materials, microcompression has instigated a great deal of interest in materials and mechanics communities due to its ease of access and straightforwardness of data interpretation, though with due caution $[42,43]$. We used the focused ion beam (FIB) technique to fabricate micrometer-sized pillars. The FIB system used was the FEI Nova 600, and AutoMike software [44] was used to mill the pillars.

The microcompression experiments were performed using nano-indenter XP with a diamond flat-punch of square cross-section, and the side length of the punch was $\sim 30 \mu \mathrm{m}$. Fig. 1 displays a micropillar of the HPT nanocrystalline $(\mathrm{NC}-)$ Ta to be tested by microcompression.

\subsection{High-rate mechanical testing}

We used the Kolsky bar (or Split-Hopkinson pressure bar) technique to measure the dynamic mechanical properties of the HPT NC-Ta. Since the specimen is very small, 


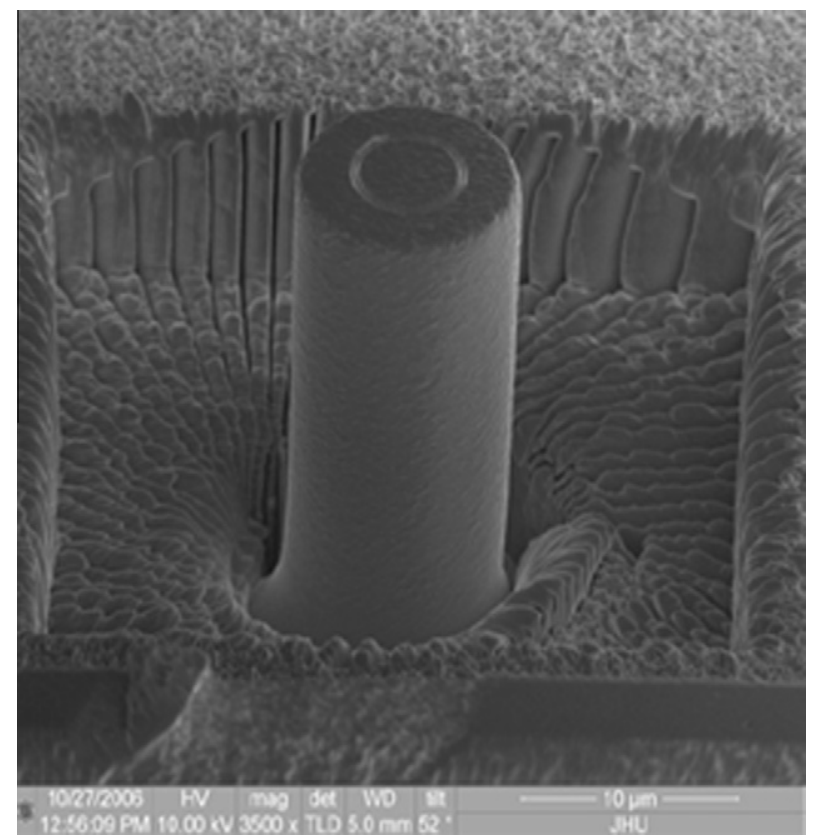

Fig. 1. Micropillar of nanocrystalline tantalum fabricated by FIB for the microcompression experiment. The diameter of the pillar is less than $10 \mu \mathrm{m}$.

we had to use a miniaturized system (or desktop Kolsky bar: DTKB [45]). Fig. 2 provides a schematic of the DTKB system used in this work. The detailed working principle and data processing methods can be found in Ref. [46]. Briefly, a projectile is launched from a gun barrel by the pressurized gas released from the gas tank. The projectile impacts on the input bar and generates a stress wave that travels down the bar. The specimen is sandwiched between the input bar and the output bar. When the stress wave arrives at the input bar/specimen interface, part of the wave is reflected and part taken up by the specimen, which is dissipated by the deformation/failure of the specimen. Another part is transmitted from the specimen to the output bar. Afterwards the stress wave is transmitted to a momentum trap made of lead. Strain gages are attached to the input and output bars, and signals are collected by a multiple-channel high-speed oscilloscope. Signals from the reflected wave provide information on the strain history of the specimen, and those from the transmitted wave provide information on the stress history of the specimen [47]. Processing of the stress wave signals allows one to derive the high-strain-rate (strain rate of the order of $10^{3} \mathrm{~s}^{-1}$ and beyond) stress-strain behavior of the specimen. Certain requirements need to be satisfied regarding the specimen dimensions so that the stress-strain curves thus obtained are faithful measure of the materials behavior.

Both the loading faces and side faces of the rectangular specimens were carefully polished. After the dynamic testing, the specimens were recovered for surface morphology observations using scanning electron microscopy for any evidence of adiabatic shear localizations.

\section{Experimental results}

In what follows, we will first present experimental results on the microstructures of the HPT-processed nanocrystalline tantalum based on X-ray diffraction (XRD) and trans-
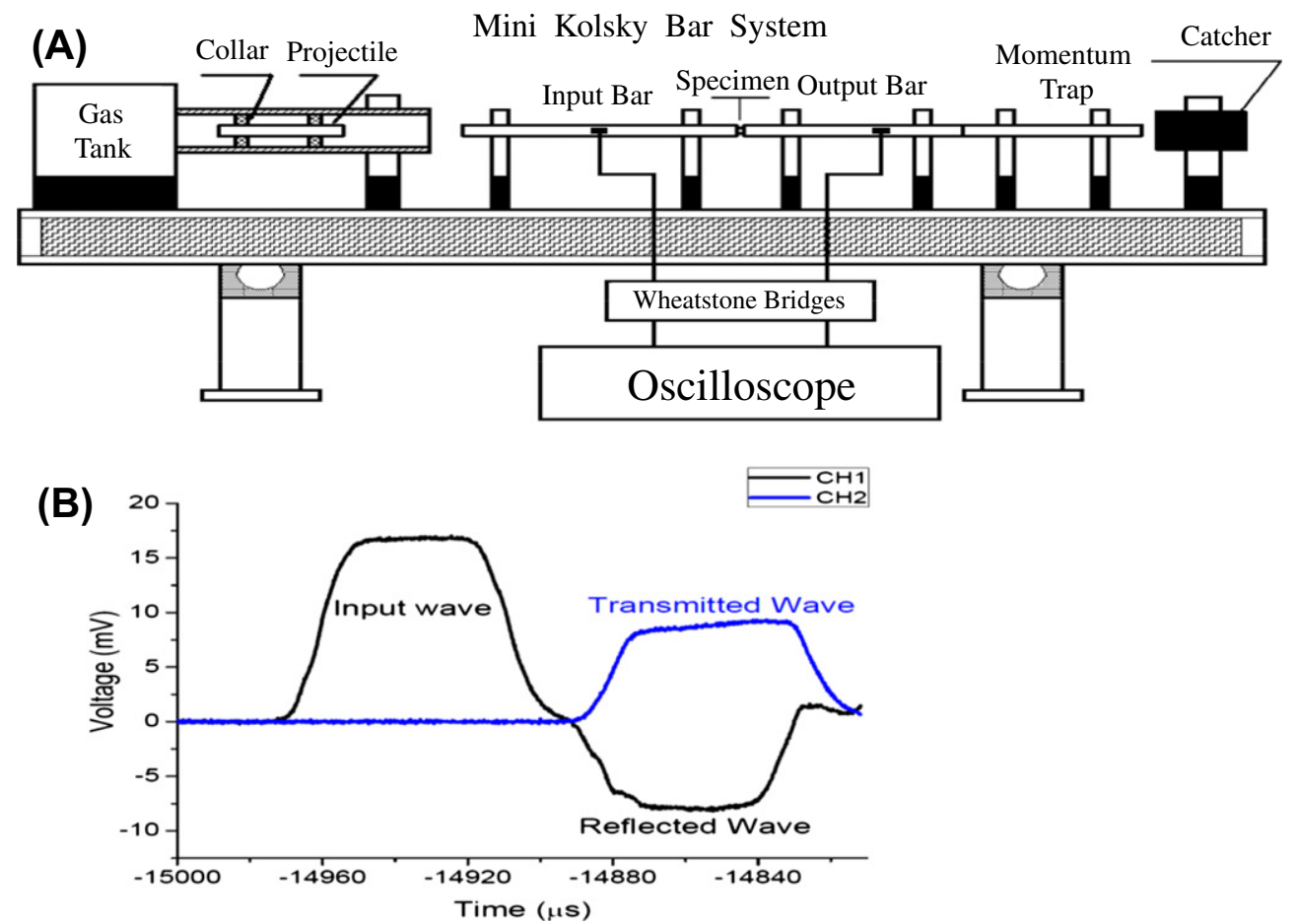

Fig. 2. (A) Schematic of the desktop Kolsky bar system for the high-strain-rate mechanical testing. The projectile, input bar, output bar and the momentum trap are all made of the same ultrastrong maraging steel with the same diameter of $5 \mathrm{~mm}$. (B) Typical signals from a single experiment. 
mission electron microscopy (TEM) analysis, including the grain size measurement from X-ray line broadening, TEM examination, grain boundary structure and dislocations. We will then present the nanoindentation results, including hardness at different locations of the HPT disk and strain rate sensitivity, followed by the microcompression results. Finally, we will provide high-strain-rate stress-strain curves of the HPT tantalum samples and post-loading scanning electron micrographs to show the occurrence, if any, of adiabatic shear bands.

\subsection{Microstructures of the HPT tantalum}

Fig. 3 displays the results for grain size based on X-ray diffraction line broadening analysis. The grain size results are from the four low-index reflections. Fig. 3 shows that analysis of the XRD peak broadening from (1 110$)$ planes results in an average grain size of $\sim 35 \mathrm{~nm}$, and other peaks give much smaller grain sizes. This is not surprising, as pointed out by Warren [48] and observed and analyzed by Jiang and co-workers [49]. XRD also shows that the HPT tantalum exclusively exhibits a bcc structure, i.e. no phase transformation takes place during HPT process.

Fig. 4a presents a bright-field TEM image of the HPT tantalum. It shows that, unlike HPT tungsten, in which severely elongated grains are observed [50], HPT-Ta exhibits equiaxed grains. It also shows that the grain size of the vast majority of the grains is below $100 \mathrm{~nm}$. The dark-field TEM image shown in Fig. 4b confirms this observation. The selected area diffraction pattern of Fig. $4 \mathrm{c}$ shows a continuous ring pattern, implying the absence of texture in the HPT Ta and very fine grains.

To have a better sense of the grain size and its distribution in the specimen, we performed a quantitative measurement of the grain size based on the TEM images. Fig. 5

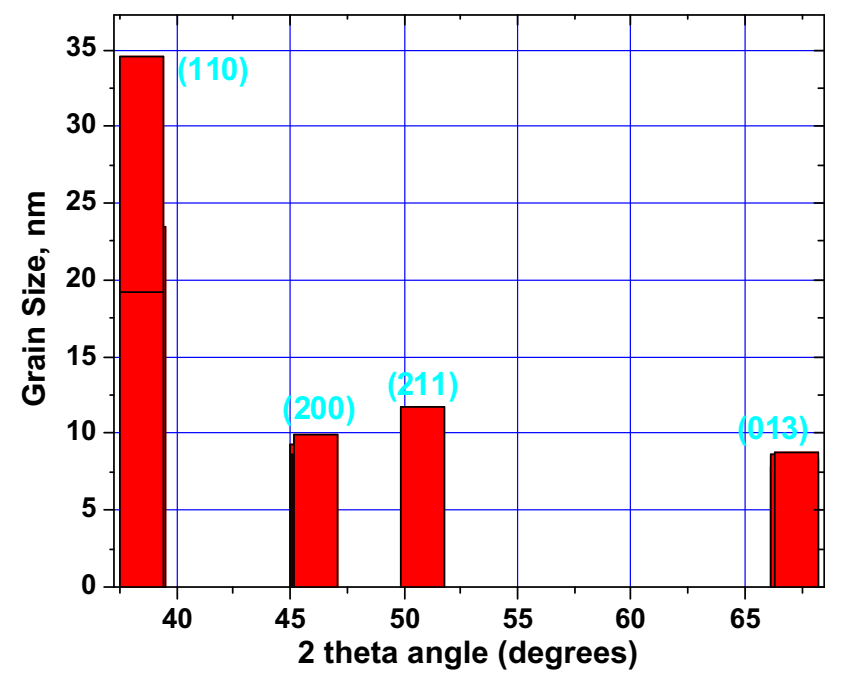

Fig. 3. Results of grain size measurement based on XRD peak broadening analysis of the four low-index planes of HPT nanocrystalline tantalum. The plot shows that broadening of ( $\left.\begin{array}{lll}1 & 1 & 0\end{array}\right)$ peaks gives the largest grain size, while other peaks consistently give a much smaller grain size estimation. Each peak corresponds to three individual measurements.

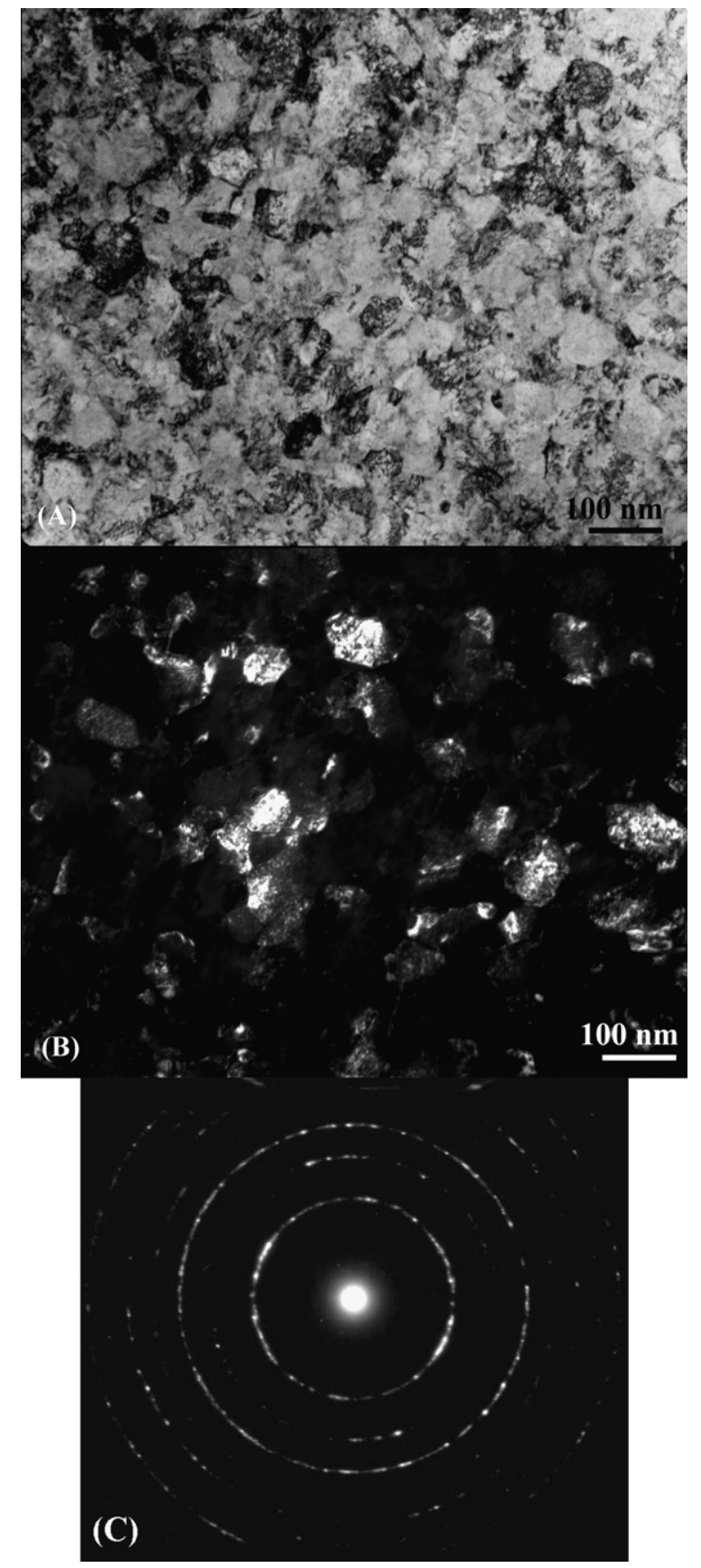

Fig. 4. (A) Bright-field TEM image taken from the HPT nanocrystalline tantalum. Equiaxed grains have formed. Many grains exhibit contrast, obviously from dislocations. (B) Dark-field TEM image corresponding to (A), again showing equiaxed grains. (C) Selected area diffraction pattern showing continuous rings, suggesting very fine grains and the absence of apparent texture.

shows the grain size distribution based on the analysis of more than 250 grains. It suggests that the majority of the grains have a grain size less than $50 \mathrm{~nm}$, and the average grain size based on statistical analysis is $43.8 \mathrm{~nm}$. It should be noted that the TEM grain size is slightly larger than the XRD grain size. This apparent discrepancy has been reported and carefully analyzed by Jiang and co-workers [49]. 
Both the bright-field and dark-field TEM images suggest that the HPT nanocrystalline Ta has a high density of dislocations. This observation is further asserted by high-resolution TEM, as shown in Fig. 6, where dislocations have been marked out for better visibility. This microstructural character is similar to HPT tungsten [50], in which highdensity edge dislocations have been observed within the tiny grains. Analysis of a number of HRTEM images indicates that the average dislocation density within the tiny grains is of the order of $\sim 10^{16} \mathrm{~m}^{-2}$.

Fig. 7 shows an HRTEM image of two neighboring grains. The grain boundaries are found to be decorated with atomic steps, ledges and dislocations. The figure also shows that the dislocation density is high in the close vicinity of the grain boundary. This implies that the grain boundaries in HPT nanocrystalline Ta are non-equilibrium and have high energy [51].

In summary, we have obtained truly nanocrystalline tantalum via HPT at room temperature. The average grain size close to the disk edge is less than $50 \mathrm{~nm}$. The grains are mostly equiaxed, separated by large-angle grain boundaries. The grain boundaries are characterized by a large population of atomic steps and ledges, and high-density dislocations in their close neighborhood. High-density dislocations are also present in the grain interiors.

\subsection{Nanoindentation and microcompression results}

Fig. 8 gives the radial microhardness profile of HPT Ta. It shows that at least within $2 / 3$ of the radius the microhardness is relatively uniform, implying homogeneous microstructure of the HPT Ta. Taking the average microhardness at the outer edge of the disk to be $4.1 \mathrm{GPa}$, the average grain size of the HPT Ta in this region can be estimated using the Hall-Petch relation for Ta [52],

$H=780+690 d^{-1 / 2}$

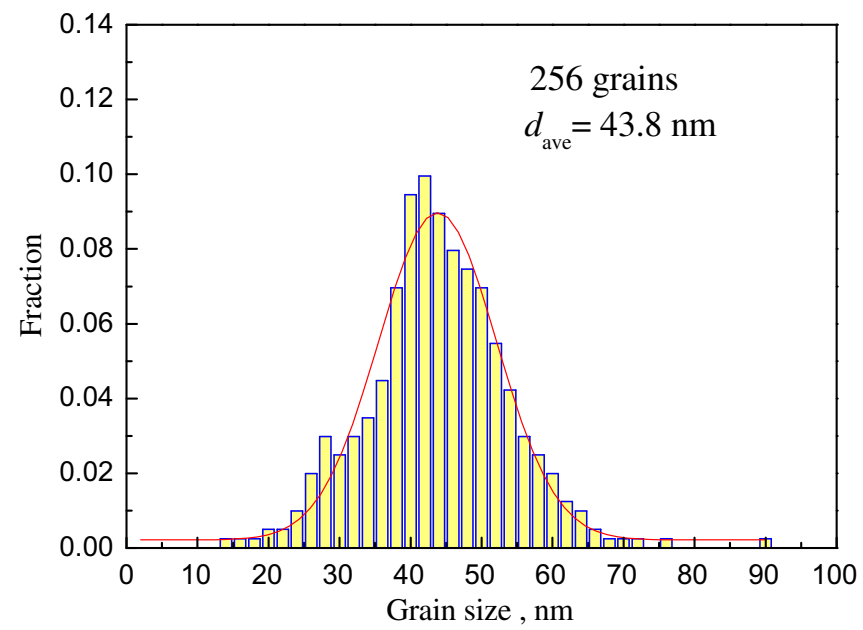

Fig. 5. Grain size distribution of HPT tantalum based on TEM analysis. The majority of the grains have sizes centered at $\sim 40 \mathrm{~nm}$. The average grain size is $43.8 \mathrm{~nm}$.

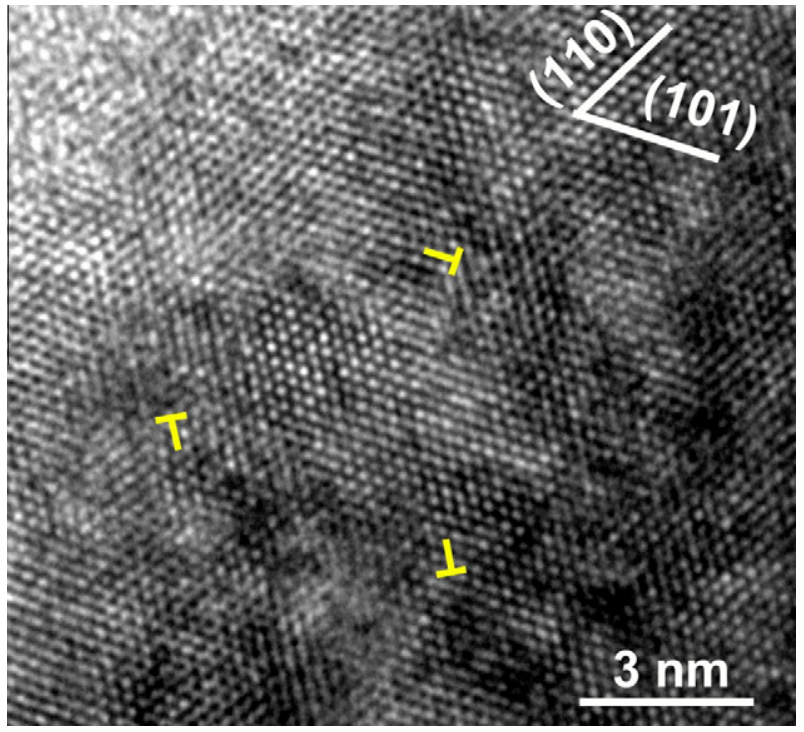

Fig. 6. High-resolution TEM image of HPT Ta showing the high density of dislocations, with three dislocations marked by arrows.

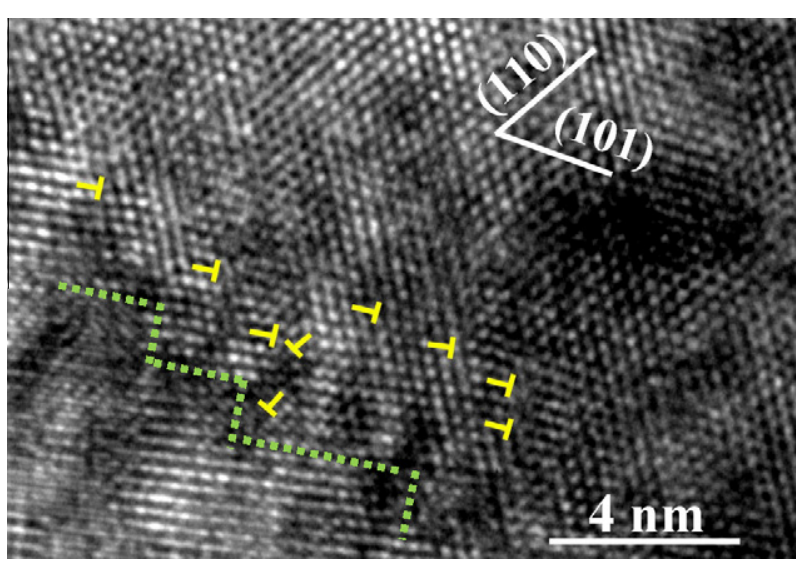

Fig. 7. HRTEM image of a non-equilibrium grain boundary. Grain boundary dislocations are marked by arrows. Also seen in the image are the atomic steps and ledges at the grain boundary (shown by the broken line segments).

In Eq. (4), $H$ is the hardness in MPa and $d$ is the grain size in $\mu \mathrm{m}$. Based on Eq. (4), the average grain size at the outer edge of the disk is $\sim 43 \mathrm{~nm}$, which is very close to the TEM grain size of the specimen. However, at the center the hardness is only $2.5 \mathrm{GPa}$, and the Hall-Petch relation results in an average grain size of $160 \mathrm{~nm}$. This is above the upper bound of the nanocrystalline regime, but it is still much finer than achievable via equal-channel angular extrusion [53].

To further examine the hardness as well as the elastic modulus of the HPT Ta, we performed instrumented nanoindentaion on the samples. In order to evaluate the effect of loading rate on the nanoindentation hardness of the samples, we performed nanoindenation at three nominal strain rates: $0.2,0.4$ and $0.8 \mathrm{~s}^{-1}$. The strain rate sensitivity (SRS) is calculated using Eq. (2). Table 1 shows the nanohardness at the edge of the specimen and at $2 \mathrm{~mm}$ away from the 


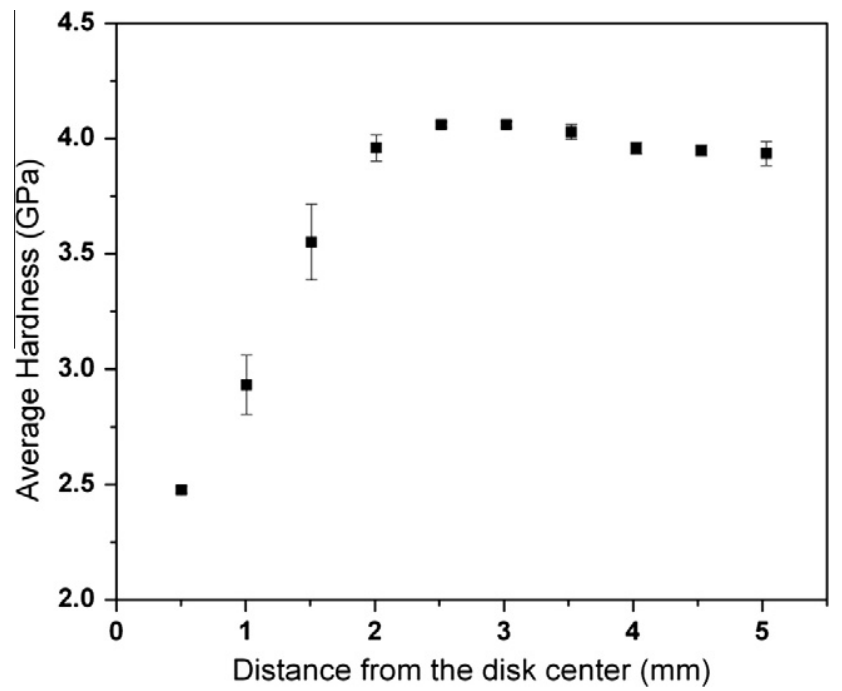

Fig. 8. Microhardness profile of the HPT Ta.

disk center. Fig. 9 shows the fitting of the hardness data vs. the nominal strain rate (both in logarithmic scale). It shows that the SRS of the NC Ta at the HPT disk edge is $\sim 0.11$, while that at $2 \mathrm{~mm}$ from the disk center is $\sim 0.08$. Both SRS values are significantly larger than those of coarse-grained $\mathrm{Ta}(\sim 0.045,[54])$ as well as ultrafine-grained Ta processed by equal-channel angular pressing $(\sim 0.025[38,53,55])$.

The elastic modulus of the HPT nanocrystalline Ta is $\sim 170 \mathrm{GPa}$, smaller than the bulk value (186 GPa) [56]. A possible explanation for this observation will be given in Section 4.

Fig. 10 shows the compressive stress-strain curves of the HPT Ta with samples fabricated by FIB at different locations of the HPT disk. To examine the specimen size effect of nanocrystalline $\mathrm{Ta}$, pillars of different diameters were also fabricated and tested. The nominal strain rate of all the tests was kept at $\sim 10^{-4} \mathrm{~s}^{-1}$. We found that the stress-strain behavior depends on the location of the pillars on the disk. The specimens with diameters of 5 and $10 \mu \mathrm{m}$ fabricated from the same radial location on the HPT disk show almost identical stress-strain behavior, except that the thinner pillar shows plastic instability, as the significant "flow softening" suggests.

\subsection{High-strain-rate mechanical behavior of the HPT tantalum}

Here we first present the dynamic stress-strain curves of the HPT tantalum, followed by post-mortem SEM observations.

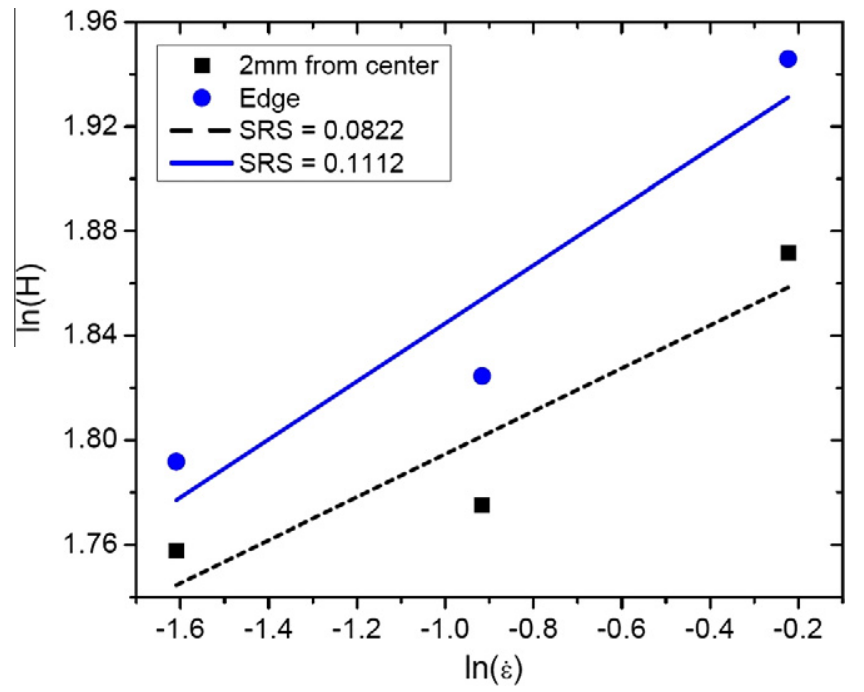

Fig. 9. Logarithmic nanohardness vs. logarithmic nominal strain rate at the edge and at $2 \mathrm{~mm}$ away from the center of the HPT Ta disk. The SRS values for the two locations are also given in the inset of the plot. The hardness is in GPa and the nominal strain rate is in $\mathrm{s}^{-1}$.

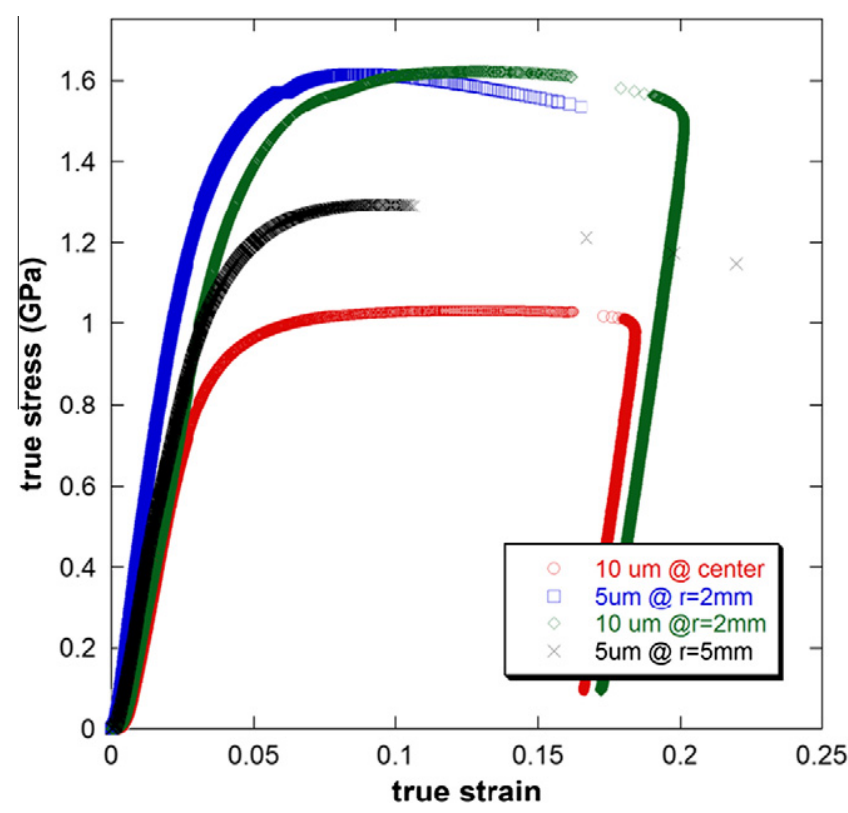

Fig. 10. Compressive true stress-true strain curves from microcompression experiments on HPT Ta micropillars at different locations and with different pillar diameters. The legend in the figure shows the pillar diameter and the location of the pillar on the HPT disk. For example, the first (circle) legend means that the pillar diameter is $10 \mu \mathrm{m}$ and the pillar is at the center of the disk. Two pillars at $2 \mathrm{~mm}$ from the disk center with diameters of 5 and $10 \mu \mathrm{m}$, respectively, have almost identical stress-strain behavior except that the $5 \mu \mathrm{m}$ pillar shows softening upon yielding.

Table 1

Nanoindentation hardness of HPT disk at two different locations and at three different strain rates at each location.

\begin{tabular}{lll}
\hline Nominal strain rate $\left(\mathrm{s}^{-1}\right)$ & Nanohardness at $2 \mathrm{~mm}$ from disk center $(\mathrm{GPa})$ & Nanohardness at the disk edge $(\mathrm{GPa})$ \\
\hline 0.2 & 5.8 & 6.0 \\
0.4 & 6.0 & 6.2 \\
0.8 & 6.5 & 6.9 \\
\hline
\end{tabular}




\subsubsection{Dynamic stress-strain curves}

Fig. 11 shows the representative dynamic stress-strain curves of HPT tantalum samples cut from different locations from the HPT disk. The true stress-true strain curves were measured using the desktop Kolsky bar (DTKB) system (Fig. 2). Depending on the locations of the specimens on the HPT disk, strikingly different dynamic mechanical behaviors are observed. We should first point out that the load drop at the end of each dynamic stress-strain curve is not due to sample failure, but is because the prescribed strain has been reached. The first group of dynamic stress-strain curves, those of samples 1 and 3, which were cut close to the center of the HPT disk, taken at strain rates of 3300 and $7900 \mathrm{~s}^{-1}$, respectively, show peak flow stresses of $\sim 1400$ and $1200 \mathrm{MPa}$, respectively. Both samples show higher dynamic flow stress than the ultrafine-grained $\mathrm{Ta}$ reported in Ref. [53]. The stress-strain curves of both samples exhibit steady flow softening, reminiscent of the dynamic stress-strain curves of ultrafine-grained $\mathrm{Ta}, \mathrm{W}$ and $\mathrm{Fe}$, processed by equal-channel angular pressing $[53,57-61]$. However, the flow softening is more severe than that of ultrafine-grained Ta [53]. The second group of dynamic stress-strain curves include those of samples 2, 4, 6 and 7, which were cut a distance away from the disk center. These curves show peak dynamic stress up to $2000 \mathrm{MPa}$ and various degrees of dynamic flow softening. Apparently, the dynamic flow softening of this group is more severe than in the samples from the first group (samples 1 and 3). The last sample (sample 5), tested at a strain rate of $7500 \mathrm{~s}^{-1}$, shows a peak dynamic flow stress slightly above $2000 \mathrm{MPa}$ and a precipitous stress drop immediately following yielding. This behavior is similar to that of HPT W under dynamic loading [50]. Such dynamic stress-strain behavior suggests that the high-rate plastic deformation mode of this sample should be quite different from the samples of the first two groups. This will become clear in the section to follow as we examine the post-loading surfaces of the various samples.

\subsubsection{Post-mortem SEM observations}

Based on the dynamic stress-strain curves presented in the previous section, we can classify the samples into three distinct groups. We observe that the flow stress level, the dynamic flow softening, stress drop, and so on, of these groups are quite different from one another. To understand the underlying mechanisms that lead to the different behaviors, we examine the post-mortem SEM morphologies of the pre-polished side faces of the dynamic samples.

Fig. 12 displays the post-loading images of representative samples from the aforementioned three groups. In all images, the loading wave is in the vertical direction. Fig. 12a is from sample 3 (first group) of Fig. 11. Diffuse localized shearing can be observed from this low-magnification image, akin to the ultrafine-grained Fe produced by equal-channel angular pressing (ECAP) [58]. An enlarged SEM image of the boxed area of Fig. 12a is presented in Fig. 12b, which provides a better view of the diffuse localized shearing, as suggested by the directionality of the flow lines running from the top right to the bottom left of the specimen, again reminiscent of what was observed in ultrafine-grained $\mathrm{Fe}$ under similar loading conditions. This explains the more severe flow softening in the HPT Ta than in the ultrafine-grained Ta (produced by ECAP) [53].

Fig. 12c is taken from sample 4 (the second group). It shows a primary adiabatic shear band (ASB). The shear offset is obvious in this image. Taking into account the dynamic stress-strain curve of this sample (Fig. 11), we

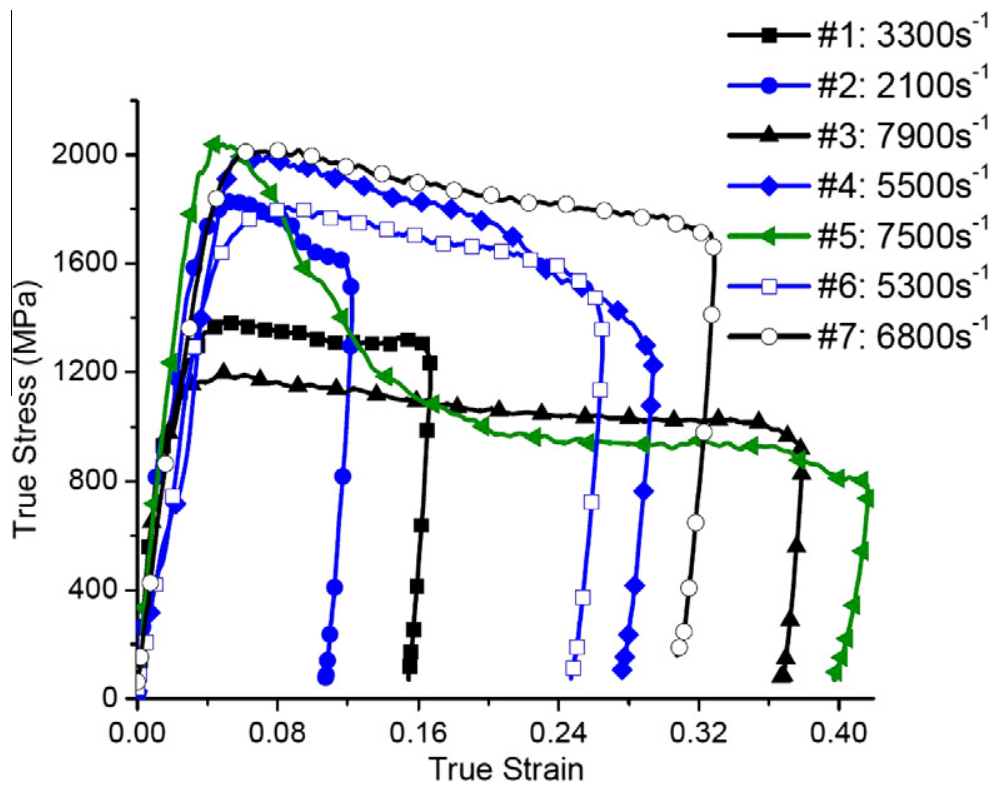

Fig. 11. High-strain-rate uniaxial compressive stress-strain curves of HPT-Ta samples cut from different locations of the HPT disk. Note the dynamic flow softening of all the specimens. The final load drop is not because of specimen failure, but because the prescribed strain has been reached. Sample \#5 stands out from the group as it shows a precipitous stress drop immediately after yielding. 

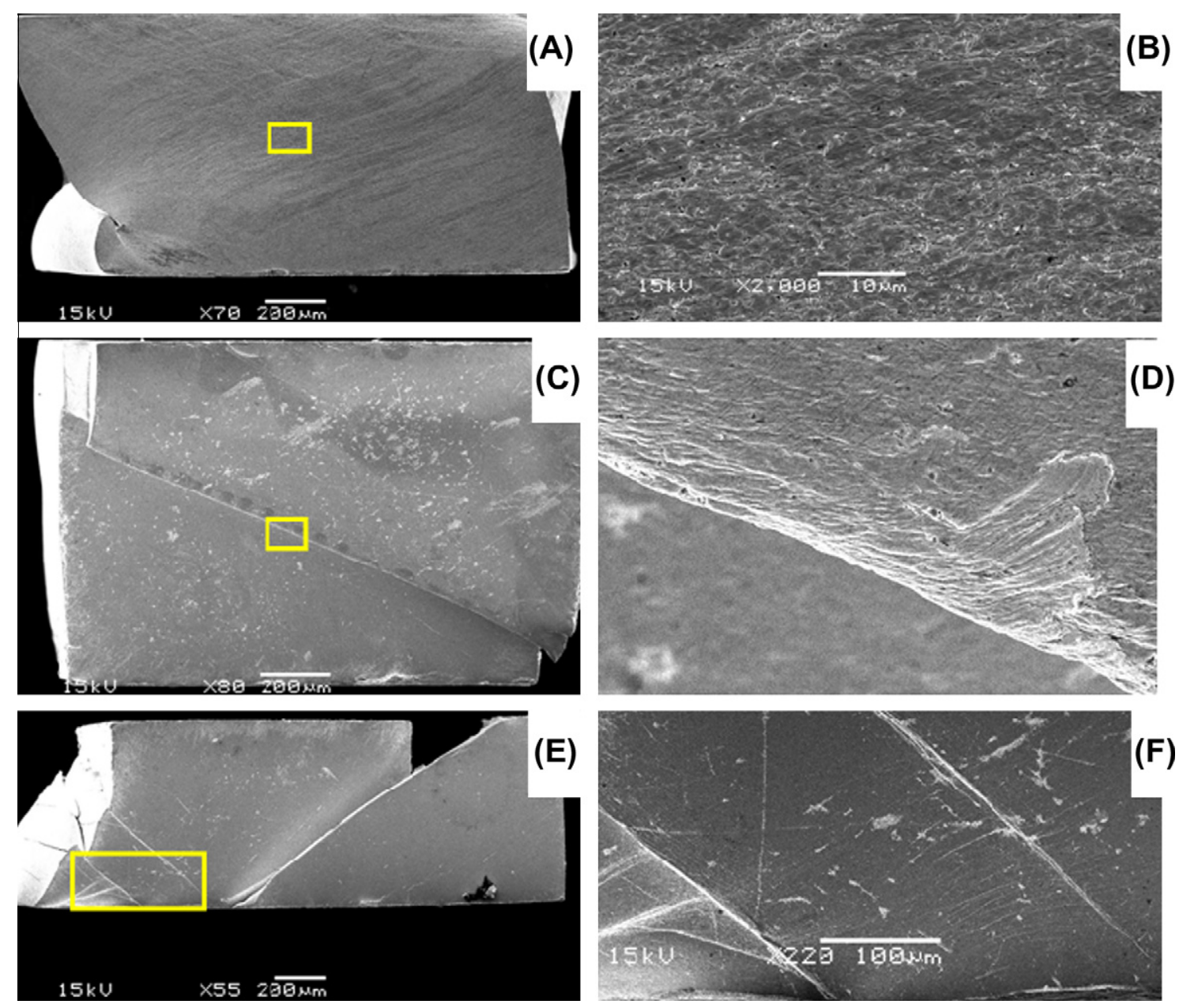

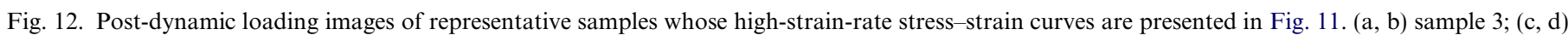

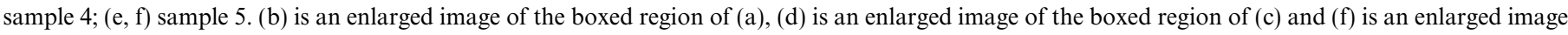
of the boxed region of (e).

presume that the shear band kicks in at a true strain of about 0.18 , after which a sharper stress drop appears, signaling the initiation and development of the primary ASB. This ASB notwithstanding, the specimen did not fall into fragments but remains whole and still sustains the subsequent loading. If we enlarge the ASB region, as shown in Fig. 12d, we can observe severely localized adiabatic shearing within and close to the ASB. The flow lines enter into the ASB and then curve away from it, in keeping with the typical canonical patterns, in the sense of Wright [62], of fully formed ASBs observed in numerous viscoplastic materials.

Fig. 12e is from sample 5 of Fig. 11. The dynamic stressstrain curve reach a peak stress and then a sudden stress drop appears. This is in accordance with the post-loading examination of the specimen surface, where a major adiabatic shear band is observed followed by secondary or even tertiary ASBs. It can also be seen that, even though the total strain of the specimen is quite significant, the strain is primarily concentrated within the ASBs, implying that plastic instability had kicked in at a very early stage of plastic deformation. An enlarged view of the secondary and tertiary shear bands as displayed in Fig. 12f shows the shear offset of the pre-existing polishing scratches. Again, the typical canonical shear flow pattern is observed.

In summary, post-mortem SEM examination of the HPT-Ta samples suggests that adiabatic shear banding is the dominant plastic deformation mechanism for these samples under high-strain-rate uniaxial compression. This observation explains in part the strong dynamic flow softening as represented by the dynamic stress-strain curves of Fig. 11. However, the extent of the localized shearing upon high-strain-rate loading depends on the flow stress of the specimens, which in turn is determined by the location of each specific dynamic specimen on the HPT disk. Specimens located close to the center of the disk exhibit only diffuse ASB, while those close to the disk edge with very high flow stresses show severely localized flow localization. Some specimens (sample 5, for example) even develop secondary and tertiary ASBs, and such plastic instability commences at the very earliest stage of plastic deformation. As such, the vast majority of the plastic strain is localized within the ASB, and the stress collapse takes place immediately after plastic yielding upon high-rate loading. 


\section{Discussion}

In the previous section we presented experimental results on the microstructure, nano/microscale mechanical properties at various quasi-static strain rates, and high-rate properties of the HPT-processed nanocrystalline Ta. In this section, we will provide in-depth discussion on the experimental results.

First of all, it should be noted that tantalum is a typical refractory metal with bcc structure. Its high melting point of $\sim 3290 \mathrm{~K}$ suggests that room temperature is only below $1 / 10$ of its melting point. It should also be noted that, unlike polycrystalline tungsten, which exhibits ceramic-like brittle behavior even at $300{ }^{\circ} \mathrm{C}[63,64]$, polycrystalline Ta shows ductile behavior at temperatures as low as $10 \mathrm{~K}$ [56]. Therefore, Ta serves as an excellent model material for nanocrystallization by means of SPD for the following reasons. First, it can take up a tremendous amount of plastic strain due to its extraordinary ductility. This is also manifested by the fact that Ta was reported to survive 24 passes of ECAP without obvious cracking of the workpiece [60]. However, a well-known observation is that after four passes of ECAP the hardening is almost saturated, with a quasi-static flow stress of $<1.0 \mathrm{GPa}$. Our HPT Ta shows a maximum quasi-static flow stress of $\sim 1.6 \mathrm{GPa}$ (Fig. 10), associated with an average grain size of $\sim 40 \mathrm{~nm}$. This means ECAP has an upper limit in hardening Ta and refining the grain size while HPT can go beyond this limit. Secondly, no significant dynamic recrystallization should be anticipated during room temperature HPT owing to its very high melting point. We believe it is these two characteristics of Ta that allow us to achieve truly nanocrystalline microstructure of Ta.

A distinct difference between the microstructure of bottom-up and top-down NC metals (via SPD) is that the latter is of a non-equilibrium nature. Grain boundaries of SPD-processed ultrafine-grained and nanocrystalline metals usually exhibit numerous atomic steps and ledges, which can serve as either dislocation sources or sinks $[51,65,66]$. This has been used to explain the strength-ductility paradox of some nanocrystalline metals [66]. Our TEM observations suggest that the HPT nanocrystalline Ta has a very small grain size $(\sim 40 \mathrm{~nm})$. Furthermore, the tiny grains are decorated with a large density of dislocations, both from bright-field/dark-field TEM images (Fig. 4a and b) and high-resolution TEM images (Figs. 6 and 7). We have taken a step further and measured the dislocation density. Our analysis shows that the dislocation density based on statistics of numerous HRTEM images is of the order of $\sim 10^{16} \mathrm{~m}^{-2}$. This observation suggests that the conventional notion of the lack of dislocation storage in nanometer grains may need further examination. A recent effort on the strain hardening of nanocrystalline nickel ( $\sim 20 \mathrm{~nm}$ grain size) indicates a significant increase in hardness of the specimen rolled to large plastic strains [30]. Detailed TEM observations reveal the accumulation of dislocations through the formation of Lomer-Cottrell locks. We presume that similar dislocation mechanisms, such as the formation of sessile dislocation structures might have taken place during severe plastic straining of Ta, particularly at the low homologous temperature, allowing for dislocation storage and breakdown of grain size into the truly nanoregime, and rendering large-angle grain boundaries with atomic steps, ledges and dislocations.

The SRS of the nanohardness of HPT nanocrystalline $\mathrm{Ta}$ is $\sim 0.08-0.11$. These SRS values are much higher than those of the coarse-grained Ta $(\sim 0.045)$ [54]. It has recently been observed that the SRS of fcc metals increases with decreasing grain size, primarily due to the reduced sampling size of dislocations in the course of their motion, which in turn reduces the activation volume of plastic deformation $[38,55,67,68]$. A phenomenological relation between the activation volume and SRS for plastic deformation is given by Eq. (3) above, or by other formulas of similar spirit. The important point is that an increased SRS leads to a decreased activation volume. Naturally, the physical picture associated with the activation volume serves as an indicator to pin down the mechanisms for plastic deformation of the specimen $[38,69,70]$. For example, for nanocrystalline fcc metals, the much increased SRS ( $\sim 0.03$ for nanocrystalline metals vs. $\sim 0.004$ for coarsegrained metals) leads to an activation volume of the order of a few $b^{3}$ ( $b$ is the length of the Burgers vector of the dislocations). Thus dislocation-mediated mechanisms ceases to operate and yield to the grain boundary activities such as emission of partial dislocations from grain boundaries, grain boundary sliding and shuffling.

On the other hand, it has been shown that, for bec metals, refining the grain size into the ultrafine grain regime results in a twofold decrease in the SRS [38,53,55,71,72]. For example, most coarse-grained bcc metals exhibit SRS of the order of $\sim 0.04$ at homologous temperatures below 0.25 [54], but ultrafine-grained bcc metals exhibit SRS of the order of $\sim 0.02$ [38]. This can be explained by the peculiar plastic deformation mechanisms of bec metals. It is a well-established theory that the yield strength and plastic deformation of single-crystal or coarse-grained bcc metals are strongly sensitive to temperature and the strain rate imposed by the peculiar structure of the dislocation cores of such metals [54,73-75]. Since the Burgers vector of a bcc lattice is in the $\left\langle\begin{array}{llll}1 & 1 & 1\end{array}\right\rangle$ direction, which is the zone axis of three equivalent slip planes of the (1 110$)$ family, the core of screw dislocations in bcc metals are non-planar and is spread in all three $\left(\begin{array}{lll}1 & 1 & 0\end{array}\right)$ planes [76,77]. Therefore, core contraction is needed for a screw dislocation to move in a bcc metal, and this requires a large shear stress. What is more, the yielding of bcc single-crystal metals does not obey Schmid's law, again because of the core structure of screw dislocations, which entails a strong dependence on the stress state [78-80]. As a consequence, the Peierls-Nabarro stress for screw dislocations in bcc metals is usually high, and the mobility of the screws is much smaller than that of edge dislocations [81]. In fact, the motion of screw dislocations of bcc metals is facilitated by the double-kink 
mechanism where a pair of edge kinks are formed whose lateral spreading brings the whole screw dislocation to the next Peierls-Nabarro potential valley. Since the nucleation of kink pairs can be assisted by thermal activation, the motion of screw dislocations also exhibits a strong dependence on temperature. This explains the strong rate and temperature dependence of yielding and plastic deformation of most bec metals. Based on the above, the physical activation volume for plastic deformation of a bcc metal can be written as $[38,70]$.

$v^{*}=b \cdot h \cdot \lambda^{*}$

In the above equation $b$ is the magnitude of the Burgers vector, $h$ is the height of the kink (one atomic distance) and $\lambda^{*}$ is the critical distance between the two kinks. It was shown by Seeger and Schiller $[82,83]$ that the critical distance between the two kinks of a pair depends strongly on the applied stress as follows:

$\lambda^{*}=\left(\frac{G b h}{8 \pi \sigma}\right)^{1 / 2}$

In Eq. (6), $G$ is the shear modulus and $\sigma$ is the applied stress $(G=69 \mathrm{GPa}$ for Ta). Taking $\sigma$ to be $1.6 \mathrm{GPa}$ (Fig. 10 of this work) and $h=b$ [82], the critical distance is calculated to be only $\sim 1.3 b$, which gives an activation volume of the order of $\sim 1.3 b^{3}$ from Eq. (5). While this estimated activation volume is in line with the value from Eq. (3) and based on the SRS ( 0.08-0.11) discussed above, it should definitely rule out the possibility of a double-kink mechanism in the HPT nanocrystalline Ta. Our aforementioned analysis thus suggests that grain boundary activities takes over dislocation activities in truly nanocrystalline tantalum such as investigated in this work. In other words, in a truly nanocrystalline regime, the plastic deformation mechanisms of bcc metals and fcc metals converge, and the grain size dependence of SRS of bcc metals curves up within this regime to eventually show a U-type behavior, as indicated by Fig. 13. Molecular dynamics simulations of the tensile behavior of nanocrystalline Ta (grain size $\sim 12 \mathrm{~nm}$ ) at different strain rates also show much enhanced SRS and a great deal of grain boundary activity [84].

We have mentioned that the Young's modulus of HPT nanocrystalline as probed by instrumented nanoindentation is significantly lower than the bulk value. We believe this can be partly explained by the much increased grain boundary population in the nanocrystalline metal. As the grain boundaries have an open structure compared with the crystalline lattice, they usually show reduced elastic modulus relative to the bulk material [84-86]. Another possible explanation for this observation is that SPD-processed metals have an extraordinarily high concentration of excess vacancies $[87,88]$. In fact, it has been shown that HPT can increase the vacancy concentration of a metal to the level found immediately below the melting point of the metal, $\sim 10^{-4}$. The existence of these excess vacancies will definitely bring down the elastic modulus of the nanocrys-

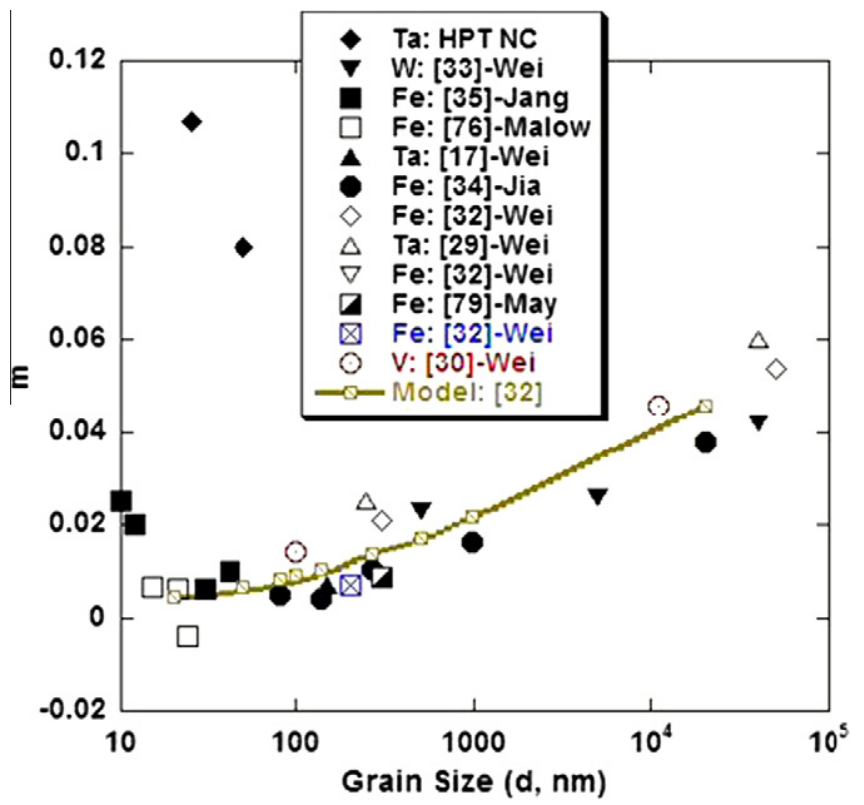

Fig. 13. SRS of bcc metals as a function of grain size. The general trend is that SRS decreases with grain size until about $100 \mathrm{~nm}$ where the decrease becomes less significant. Note the two data points for HPT nanocrystalline Ta (solid diamond). Data source for other points and the reference for the model (the inset of this figure) are to be found in Refs. [37] of this paper. Another metal with available experimental data that shows a similar trend to that of Ta is Fe. That is, when the grain size is below $100 \mathrm{~nm}$, the SRS starts to increase with further decrease in grain size.

talline metal. Finally, the texture induced by SPD may also render an elastically less stiff orientation. Detailed texture analysis is underway using synchrotron XRD, but it is beyond the scope of this article. A quantitative analysis of the specific contribution of each factor to the reduction of elastic modulus is also beyond the scope of this work.

Microcompression stress-strain curves of most of the tested pillars show elastic-perfectly plastic behavior. That is, upon yielding, the specimens enters into steady-state plastic flow without obvious strain hardening, similar to the microcompression behavior of electrodeposited nanocrystalline nickel, where the microcompression specimens were fabricated by microelectrical discharge machining $[89,90]$. However, certain samples show plastic instability, signaled by the decrease in flow stress with increased strain, as illustrated by one stress-strain curve in Fig. 10. One may be tempted to conclude that this plastic instability is due to shear banding process, as observed in consolidated $\mathrm{Fe}$ with an ultrafine-grained and nanocrystalline microstructure [91-94]. However, examination of the post-loading micropillar corresponding to the stress-strain curve (Fig. 14) suggests that the plastic instability observed in some micropillars of HPT Ta is due to plastic buckling. More specifically, Zhang and co-workers [42] show that, during microcompression, many factors affect the observed behavior of the specimen under investigation. These factors include the aspect ratio of the pillar, the misalignment between the pillar axis and the loading axis, the friction 
between the pillar top and the diamond punch, and the constitutive behavior, particularly the strain hardening behavior of the pillar material. It was shown that spurious flow softening can be induced by misalignment between the pillar and loading axes since such misalignment can easily trigger plastic buckling in the absence of strain hardening. Classical analysis of such plastic instability of columns leads to the following critical load (stress) for plastic buckling [95]:

$\sigma_{c r}^{p l}=\frac{\pi^{2} E_{t}}{(K L / \rho)^{2}}$

where $K$ is the effective length factor of the column, $L$ is the length (or height), $\rho$ is the least radius of gyration $(\rho=(I /$ $A)^{1 / 2}$, with $I$ the moment of inertia of the cross-sectional area and $A$ the cross-sectional area of the column) and $E_{t}$ is the tangent modulus of the plastic part of the true stress-strain curve. For nanocrystalline metals such as HPT Ta, the tangent modulus is nearly zero and therefore, theoretically, the critical stress for plastic buckling is nearly zero. Apparently, misalignment will exacerbate the tendency to plastic buckling. On the other hand, one factor that prevents plastic buckling from happening is the friction between the pillar top and the diamond punch. Similar plastic instability was also observed in the microcompression of nanocrystalline nickel by Schuster and co-workers [89]. Hence we can conclude that the apparent flow softening observed in certain micropillars of HPT nanocrystalline Ta is due to plastic buckling. However, shear banding may prevail under some ideal loading conditions for certain samples. A forthcoming article will deal with the competition between plastic buckling and shear localization under uniaxial compression at quasi-static rates in this HPT Ta.

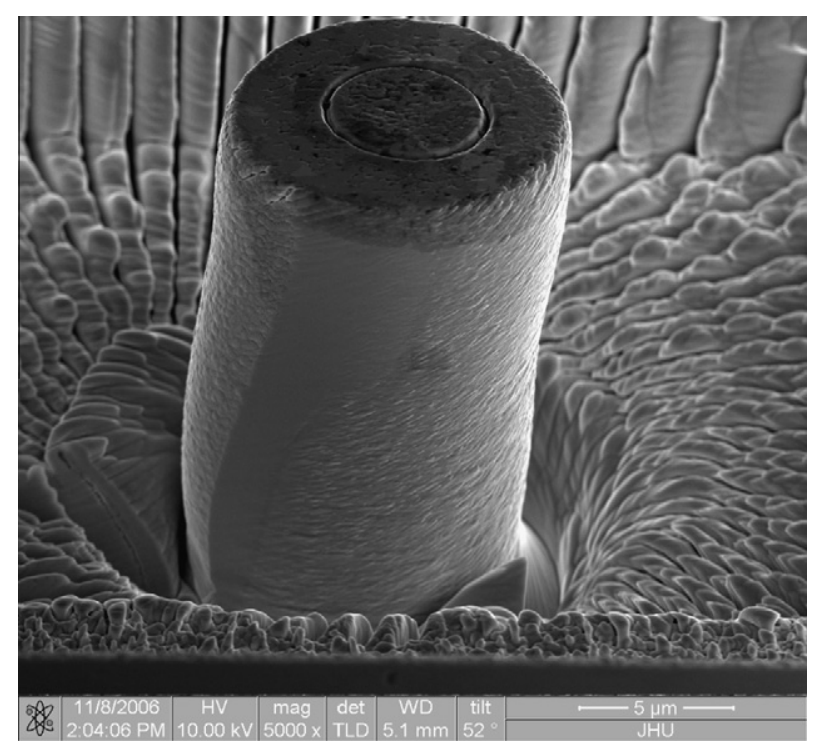

Fig. 14. Post-loading micropillar of HPT Ta showing the plastic buckling and absence of shear banding. The pillar diameter is $10 \mu \mathrm{m}$. The plastic buckling explains the plastic instability in the microcompression stressstrain curves of Fig. 10.
We have noticed that all dynamic specimens of HPT-Ta exhibit flow softening (Fig. 11). Part of this softening should come from the adiabatic temperature rise under high-rate loading of the specimens. The adiabatic temperature rise can be estimated using the following equation:

$\Delta T=\frac{\beta}{\rho C_{P}} \int_{0}^{\epsilon_{f}} \sigma d \epsilon$

where $\beta$ is the Taylor-Quinney coefficient that defines the fraction of plastic work converted into heat $(\sim 0.9$ for dynamic testing such as in this work), $\rho$ is the density of the specimen $\left(16.65 \mathrm{~g} \mathrm{~cm}^{-3}\right.$ for Ta), $C_{P}$ is the specific heat of the specimen material $\left(0.153 \mathrm{~J} \mathrm{~g}^{-1} \mathrm{~K}^{-1}\right.$ for $\left.\mathrm{Ta}\right), \sigma$ is the flow stress and $\varepsilon_{f}$ is the prescribed strain for calculation. For elastic-perfectly plastic metals such as the HPT-Ta investigated here, we can take the flow stress to be a constant, and the above equation can be simplified to

$\Delta T=\frac{\beta}{\rho C_{P}} \cdot \sigma \cdot \epsilon_{f}$

We notice that the flow stress of the dynamic specimen cut from the HPT disk center is slightly higher than that of the ECAP-processed Ta [53]. At the same prescribed strain, the overall adiabatic temperature rise should thus be slightly higher. For example, if the prescribed strain is 0.1 and the flow stress is taken to be $1.2 \mathrm{GPa}$, the adiabatic temperature rise is $\sim 50 \mathrm{~K}$.

According to Zerilli and Armstrong (Z-A) [96], the constitutive equation of Ta in terms of grain size, strain rate, temperature and strain hardening is as follows:

$\sigma=c_{0}+B_{0} \exp (-\beta T)+K \epsilon^{n}$

In Eq. (10), $c_{0}=\sigma_{G}+k_{H-P} d^{-1 / 2}$ describes the grain size strengthening; the second term describes the coupled strain-rate and temperature effects on the flow stress $(\sigma)$, where $\beta=\beta_{0}-\beta_{1} \ln \varepsilon$; the third term depicts the strain hardening in the sense of Hollomon power law. Apparently, the coefficients in Eq. (10) and the individual terms are functions of microstructure. However, in the present case, we fix the microstructure as the HPT-Ta, and therefore the strain hardening exponent $n$ of Eq. (10) is zero and the strain hardening term can be lumped into the first term as a single constant. Following Zerilli and Armstrong's work [96], $B_{0}=1110 \mathrm{MPa}, \beta_{0}=5.35 \times 10^{-3} \mathrm{~K}^{-1}$ and $\beta_{1}=3.27 \times 10^{-4} \mathrm{~K}^{-1}$. Therefore, combining Eqs. (9) and (10), we can estimate the change of flow stress vs. strain at a fixed loading rate. Fig. 15 displays the calculated dynamic stress-strain curves in juxtaposition with the experimental results of three HPT-Ta samples. It shows that the Z-A model catches the dynamic yield behavior of the various samples but apparently overestimates the flow stresses for all samples due to the flow localization of the actual samples. This is particularly evident for samples 4 and 5, where post-mortem SEM observations show strong shear localization. Keeping in mind that the Z-A constitutive relation for $\mathrm{Ta}$ is based on uniform plastic deformation, we can then reasonably propose that the 
adiabatic shear localization, diffuse or concentrated, has aggravated the dynamic softening of the high-rate specimens.

Ta has been known to strongly resist adiabatic shear banding at room temperature under uniaxial compression. Adiabatic shear localization under uniaxial dynamic compression was reported for Ta only at very low temperatures (77 K [97]). This might be due to the Debye-Einstein effect, whereby at extremely low temperatures the specific heat of $\mathrm{Ta}$ is considerably diminished, which renders Ta very prone to adiabatic shear banding [98]. Other researchers who have reported adiabatic shear banding in Ta tested at ambient temperatures used artificially concentrated shear stress by special specimen design, such as hat-shaped geometry $[97,99,100]$, or by explosive loading of thick wall tubes (strain rate $>10^{4} \mathrm{~s}^{-1}$ ) [101]. In this context, our experimental results provide the first evidence of adiabatic shear banding in pure tantalum under uniaxial dynamic compression at room temperature.

Recently, Guo and co-workers [102] have provided a numerical analysis of the effect of microstructure on the adiabatic shear localization of metals. In particular, they considered the effect of grain size on the propensity to adiabatic shear banding and applied their model to fcc and bcc metals. It was found that, in general, bcc metals exhibit an increased propensity to ASB when their grain sizes are reduced into the ultrafine-grain and nanocrystalline regime. This conclusion is consistent with many experimental results in the literature, as well as those presented here.

More quantitatively, according to Wright [62], the propensity to adiabatic shear localization of a metal can be described by the following equation:

$\frac{\chi_{S B}}{a / m}=\min \left\{1, \frac{1}{(n / m)+\sqrt{n / m}}\right\}$

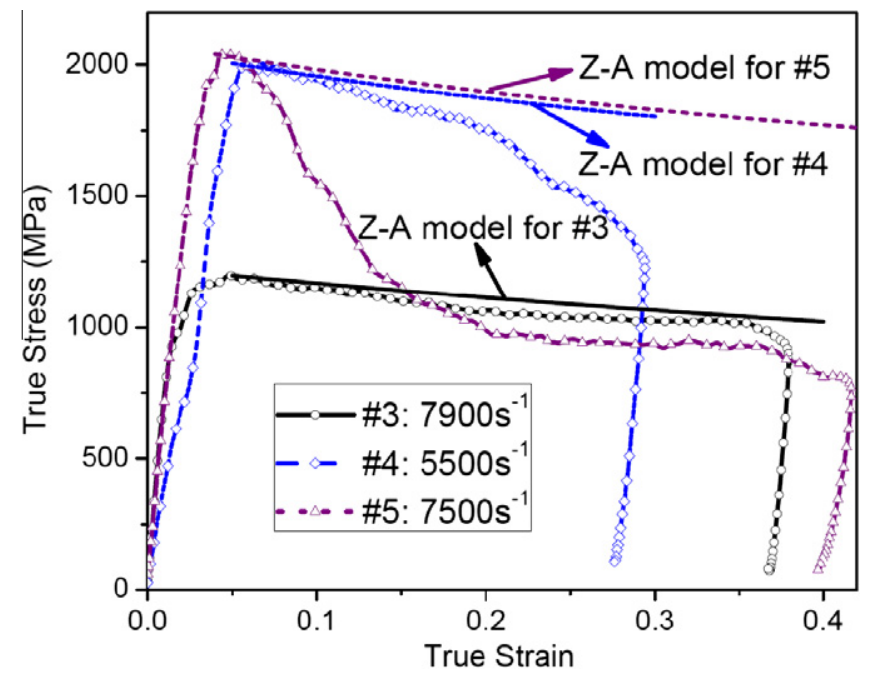

Fig. 15. Comparison of experimental dynamic stress-strain curves against the calculated dynamic stress-strain curves based on the Z-A constitutive model. The $\mathrm{Z}-\mathrm{A}$ model catches the yield behavior but overestimates the flow stress due to flow localization in the actual specimens.
In Eq. (11a), $\chi_{S B}$ is the susceptibility to adiabatic shear banding, $a$ is the non-dimensional thermal softening parameter defined by $a=(-\partial \sigma / \partial T) / \rho C_{P}$ (where $\sigma$ is the flow stress), $T$ is the temperature, $\rho$ is the material density and $C_{P}$ is the specific heat; $n$ is the strain hardening exponent (Hollomon power law work hardening) and $m$ is the SRS (power-law strain rate hardening, in the sense of this work). If we assume that the thermal softening parameter is independent of temperature at a constant microstructure, we can rewrite the above equation as

$\frac{\chi_{S B}}{a}=\min \left\{\frac{1}{m}, \frac{1}{n+\sqrt{m n}}\right\}$

Using Eq. (11b), we can evaluate the effect of strain hardening and strain rate hardening on the susceptibility to adiabatic shear banding of Ta. Based on Eq. (11b), Fig. 16 shows the effect of SRS on the susceptibility to adiabatic shear banding for different strain hardening exponents (a) and the effect of the strain hardening exponent for different SRS (b). It shows that $n$ has a stronger effect than $m$, and only when $n$ is very small is the effect of $m$ more significant. However, when $n$ is very small, the destabilizing effect of the diminished strain hardening overplays the stabilizing effect of $m$. For example, the value of $\left(\chi_{S B} / a\right)$ is $\sim 10$ for nanocrystalline Ta but only $\sim 2.0$ for coarsegrain tantalum (assuming $m=0.06$ and $n=0.3$ [53]). Another important factor that contributes to the increased tendency to adiabatic shear banding is the much higher flow stress in the nanocrystalline metal. This can be understood based on the plastic work consideration that a higher flow stress exacerbates the adiabatic heating during dynamic loading (Eq. (9)).

\section{Summary and concluding remarks}

We have investigated the microstructure of nanocrystalline tantalum with the smallest average grain size of $\sim 43 \mathrm{~nm}$ produced by HPT and examined the mechanical properties of the material at different length scales and strain rates. The important findings are summarized in the following.

We have achieved, for the first time, truly nanocrystalline microstructure of tantalum, a model bcc refractory metal in bulk form. The microstructure consists of equiaxed nanometer grains separated by large-angle grain boundaries. The grain boundaries exhibit high populations of atomic ledges and steps, and the grain interiors are decorated with high-density dislocations.

Radial hardness profiling indicates that the HPT Ta disk shows homogeneous hardness, starting at $\sim 2 \mathrm{~mm}$ from the disk center to the disk edge. Instrument nanoindentation at different nominal strain rates shows a much elevated SRS of the order of $0.08-0.11$ of nanocrystalline Ta in comparison with coarse-grained and ultrafine-grained Ta. This high SRS entails an activation volume for plastic deformation of the order of $\sim b^{3}$, which rules out conventional double-kink mechanisms for coarse-grained and ultrafine- 

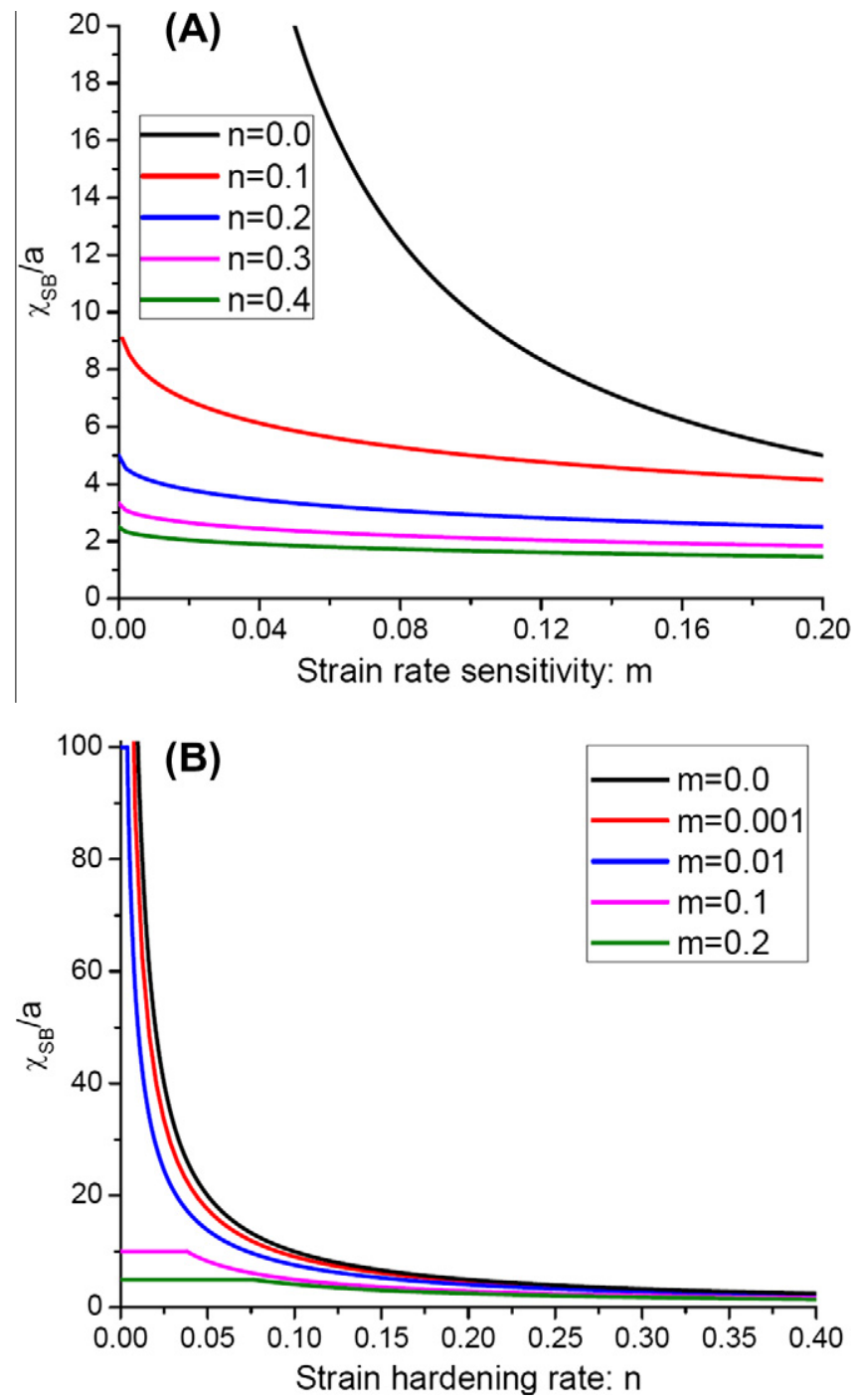

Fig. 16. (a) Effect of SRS on the susceptibility to adiabatic shear banding with different strain hardening exponents. (b) Effect of strain hardening exponent on the susceptibility to adiabatic shear banding with different SRS.

grained bcc metals. As such, we propose that in the nanocrystalline $\mathrm{Ta}$ the grain boundary-mediated mechanisms outplay screw dislocation-dominated mechanisms. Therefore, in the lower bound of the nanocrystalline regime, the plastic deformation mechanisms responsible for bcc and fcc metals converge. Instrumented nanoindentation experiments also suggest decreased elastic modulus of nanocrystalline $\mathrm{Ta}$, presumably because of the increased population of grain boundaries and the extremely high concentration of excess vacancies induced by SPD during HPT.

Microcompression of the FIB-cut pillars of the nanocrystalline Ta shows elastic-perfectly plastic stress-strain behavior. The plastic flow softening recorded in some samples is due to plastic buckling, as confirmed by post-loading SEM observations.
High-strain-rate uniaxial compression experiments of the specimens from different locations of the HPT disk all show dynamic flow softening. That is, upon yielding, the flow stress decreases with plastic strain. In many samples, sudden stress drops are observed away from the disk center. Post-mortem SEM observations of the side faces of the loaded specimens show adiabatic shear localization. For specimens near the disk center, however, only diffuse localization is present. In samples close to the disk edge, severe adiabatic shear banding is observed. Such observations were discussed based on a mechanistic model.

\section{Acknowledgements}

This work was supported by US Army Research Laboratory under Contract \# W911QX-06-C-0124. The authors would like to thank Mr. W.H. Yin for assistance in some experiments. They are also indebted to Drs. Z.G. Xu and S. Yarmolenko at NC A\&T State University for assistance with microhardness, nanoindentation and XRD measurement. X.L.W. acknowledges the support of NSFC Grant Nos. 11021262, 11072243, and 973 Project Grants Nos. 2010 CB631004 and 2009CB623700.

\section{References}

[1] Gleiter H. Prog Mater Sci 1989;33:223.

[2] Gleiter H. Acta Mater 2000;48:1.

[3] Hall EO. Proc Phys Soc B, Lond 1951;64:747.

[4] Petch NJ. J Iron Steel Inst 1953;174:25.

[5] El-Sherik AM, Erb U, Palumbo G, Aust KT. Scripta Mater 1992;27:1185.

[6] Schuh CA, Nieh TG, Yamasaki T. Scripta Mater 2002;46:735.

[7] Koch CC, Narayan J. In: Van Swygenhoven H, et al. (editors), Structure and mechanical properties of nanophase materials - theory and computer simulations vs. experiments, vol. 634. Boston, MA: MRS; 2001. p. B5.1.

[8] Nieh TG, Wadsworth J. Scripta Metall Mater 1991;25:955.

[9] Carlton CE, Ferreira PJ. Acta Mater 2007;55:3749.

[10] Scattergood RO, Koch CC. Scripta Metall Mater 1992;27:1195.

[11] Schiotz J, Di Tolla FD, Jacobsen KW. Nature 1998;391:561.

[12] Schiotz J, Jacobsen KW. Science 2003;301:1357.

[13] Meyers MA, Mishra A, Benson DJ. Prog Mater Sci 2006;51:427.

[14] Kumar KS, Van Swygenhoven H, Suresh S. Acta Mater 2003;51:5743.

[15] Dao M, Lu L, Asaro RJ, de Hosson JTM, Ma E. Acta Mater 2007;55:4041.

[16] Cheng S, Ma E, Wang YM, Kecskes LJ, Youssef KM, Koch CC, et al. Acta Mater 2005;53:1521.

[17] Sanders PG, Eastman JA, Weertman JR. Acta Mater 1997;45:4019.

[18] Youngdahl CJ, Weertman JR, Hugo RC, Kung HH. Scripta Mater 2001;44:1475.

[19] Hugo RC, Kung HH, Weertman JR, Mitra R, Knapp JA, Follstaedt DM. Acta Mater 2003;51:1937.

[20] Zhang K, Weertman JR, Eastman JA. Appl Phys Lett 2005;87:061921.

[21] Liao XZ, Kil'mametov AR, Valiev RZ, Gao HS, Li XD, Mukherjee A, et al. Appl Phys Lett 2006;88:021909.

[22] Liao XZ, Zhao YH, Srinivasan SG, Zhu YT, Valiev RZ, Gunderov DV. Appl Phys Lett 2004;84:592.

[23] Liao XZ, Zhou F, Lavernia EJ, He DW, Zhu YT. Appl Phys Lett 2003;83:5062. 
[24] Liao XZ, Zhou F, Lavernia EJ, Srinivasan SG, Baskes I, He DW, et al. Appl Phys Lett 2003;83:632.

[25] Wu XL, Liao XZ, Srinivasan SG, Zhou F, Lavernia EJ, Valiev RZ, et al. Phys Rev Lett 2008;100:095701.

[26] Wu XL, Ma E. Appl Phys Lett 2006;88:061905.

[27] Wu XL, Ma E, Zhu YT. J Mater Sci 2007;42:1427.

[28] Wu XL, Zhu YT. Appl Phys Lett 2006;89:031922.

[29] Wu XL, Zhu YT. Phys Rev Lett 2008;101:025503.

[30] Wu XL, Zhu YT, Wei YG, Wei Q. Phys Rev Lett 2009;103:205504.

[31] Kumar KS, Suresh S, Chisholm MF, Horton JA, Wang P. Acta Mater 2003;51:387.

[32] Youssef KM, Scattergood RO, Murty KL, Horton JA, Koch CC. Appl Phys Lett 2005;87:091904.

[33] Youssef KM, Scattergood RO, Murty KL, Koch CC. Appl Phys Lett 2004;85:929.

[34] Gianola DS, Van Petegem S, Legros M, Brandstetter S, Van Swygenhoven H, Hemker KJ. Acta Mater 2006;54:2253.

[35] Chen MW, Ma E, Hemker KJ, Sheng HW, Wang YM, Cheng XM. Science 2003;300:1275.

[36] Koch CC, Ovid'ko IA, Seal S, Veprek S. Structural nanocrystalline materials - fundamentals and applications. Cambridge: Cambridge University Press; 2007.

[37] Zhilyaev AP, Langdon TG. Prog Mater Sci 2008;53:893.

[38] Wei Q. J Mater Sci 2007;42:1709.

[39] Zhao YH, Guo YZ, Wei Q, Dangelewicz AM, Xu C, Zhu YT, et al. Scripta Mater 2008;59:627.

[40] Zhao YH, Guo YZ, Wei Q, Topping TD, Dangelewicz AM, Zhu YT, et al. Mater Sci Eng A 2009:525 68.

[41] Uchic MD, Dimiduk DM, Florando JN, Nix WD. Science 2004;305:986.

[42] Zhang H, Schuster BE, Wei Q, Ramesh KT. Scripta Mater 2006;54:181.

[43] Guo YZ, Li YL, Wu XL, Wei Q. Mater Sci Eng A 2010;527:2613.

[44] Uchic MD, Dimiduk DM. Mater Sci Eng A 2005;400-401:268.

[45] Jia D, Ramesh KT. Exp Mech 2004;44:445.

[46] Follansbee PS. High strain rate compression testing. ASM Metals Handbook, vol. 8. Materials Park, OH: ASM International; 1985. p. 190.

[47] Kolsky H. Stress waves in solids. New York: Dover Publications, Inc.; 1963

[48] Warren BE. X-ray diffraction. New York: Dover Publications, Inc.; 1990.

[49] Jiang HG, Ruhle M, Lavernia EJ. J Mater Res 1999;14:549.

[50] Wei Q, Zhang H, Schuster BE, Ramesh KT, Valiev RZ, Kecskes LJ, et al. Acta Mater 2006;54:4079.

[51] Nazarov AA, Romanov AE, Valiev RZ. Acta Metall Mater 1993;41:1033.

[52] Hartwig KT, Mathaudhu SN, Maier HJ, Karaman I. In: Zhu YT, Langdon TG, Mishra RS, Semiatin SL, Saran MJ, Lowe TC (editors), Ultrafine grained materials II. Warrendale, PA: TMS; 2002. p. 151.

[53] Wei Q, Jiao T, Mathaudhu SN, Ma E, Hartwig KT, Ramesh KT. Mater Sci Eng A 2003;358:266.

[54] Conrad H. The cryogenic properties of metals. In: Zackey VF, editor. High-Strength Materials. New York: Wiley; 1965. p. 436.

[55] Wei Q, Cheng S, Ramesh KT, Ma E. Mater Sci Eng A 2004;381:71.

[56] Tietz TE, Wilson JW. Behavior and properties of refractory metals. Stanford, CA: Stanford University Press; 1965.

[57] Wei Q, Jiao T, Ramesh KT, Ma E, Kecskes LJ, Magness L, et al. Acta Mater 2006;54:77.

[58] Wei Q, Kecskes LJ, Jiao T, Hartwig KT, Ramesh KT, Ma E. Acta Mater 2004;52:1859.
[59] Wei Q, Ramesh KT, Kecskes LJ, Mathaudhu SN, Hartwig KT. Mater Sci Forum 2008;579:75.

[60] Wei Q, Schuster BE, Mathaudhu SN, Hartwig KT, Kecskes LJ, Dowding RJ, et al. Mater Sci Eng A 2008;493:58.

[61] Pan Z, Guo YZ, Mathaudhu SN, Kecskes LJ, Hartwig KT, Wei Q. J Mater Sci 2008;43:7379.

[62] Wright TW. The physics and mathematics of ASBs. Cambridge: Cambridge University Press; 2002.

[63] Kecskes LJ, Cho KC, Dowding RJ, Schuster BE, Valiev RZ, Wei Q. Mater Sci Eng A 2007;467:33.

[64] Wei Q, Ramesh KT, Schuster BE, Kecskes LJ, Dowding RJ. JOM 2006;58:40.

[65] Li JCM. Trans Metall Soc AIME 1963;227:239.

[66] Valiev RZ, Estrin Y, Horita Z, Langdon TG, Zehetbauer M, Zhu YT. JOM 2006;58:33.

[67] Wang YM, Ma E. Mater Sci Eng A 2004;375-377:46.

[68] Asaro RJ, Suresh S. Acta Mater 2005;53:3369.

[69] Kocks UF, Argon AS, Ashby MF. Prog Mater Sci 1975;19:1

[70] Taylor G. Prog Mater Sci 1992;36:29.

[71] Wei Q, Kecskes LJ. Mater Sci Eng A 2008;491:62.

[72] Jia D, Ramesh KT, Ma E. Acta Mater 2003;51:3495.

[73] Christian JW. Metall Trans A 1983;14:1237.

[74] Tang M, Kubin LP, Canova GR. Acta Mater 1998;46:3221.

[75] Seeger A. Zeit Metall 1981;72:369.

[76] Vitek V. Cryst Lattice Defects 1974;5:1.

[77] Duesbery MS, Vitek V. Acta Mater 1998;46:1481.

[78] Gröger R, Bailey AG, Vitek V. Acta Mater 2008;56:5401.

[79] Gröger R, Racherla V, Bassani JL, Vitek V. Acta Mater 2008;56:5412.

[80] Gröger R, Vitek V. Acta Mater 2008;56:5426.

[81] Duesbery MS, Xu W. Scripta Mater 1998;39:283.

[82] Hirth JP, Lothe J. Theory of dislocations. Malabar, FL: Krieger Publishing Company; 1992.

[83] Seeger A, Schiller P. Acta Metall 1962;10:348.

[84] Pan ZL, Li YL, Wei Q. Acta Mater 2008;56:3470.

[85] Shen TD, Koch CC, Tsui TY. J Mater Res 1995;10:2892.

[86] Latapie A, Farkas D. Scripta Mater 2003;48:611.

[87] Kiritani M, Satoh Y, Kizuka Y, Arakawa K, Ogasawara Y, Arai S, et al. Phil Mag Lett 1999;79:797.

[88] Zehetbauer MJ, Steiner G, Schafler E, Korznikov A, Korznikova E. Mater Sci Forum 2006;503-504:57.

[89] Schuster BE, Wei Q, Zhang H, Ramesh KT. Appl Phys Lett 2006;88:103112.

[90] Pan D, Kuwano S, Fujita T, Chen MW. Nano Lett 2008;7:2108.

[91] Wei Q, Jia D, Ramesh KT, Ma E. Appl Phys Lett 2002;81:1240.

[92] Cheng S, Milligan WW, Wang XL, Choo H, Liaw PK. Mater Sci Eng A 2008;493:226.

[93] Malow TR, Koch CC. Acta Mater 1998;46:6459.

[94] Malow TR, Koch CC, Miraglia PQ, Murty KL. Mater Sci Eng A 1998;252:36.

[95] Gere JM. Mech Mater. Toronto: Thomson Press; 2006.

[96] Zerilli FJ, Armstrong RW. J Appl Phys 1990;68:1580.

[97] Chen Y-J, Meyers MA, Nesterenko VF. Mater Sci Eng A 1999;268:70.

[98] Rogers HC. Annu Rev Mater Sci 1979;9:283.

[99] Meyers MA, Chen Y-J, Marquis FDS, Kim DS. Metall Mater Trans A $1995 ; 26: 2493$.

[100] Perez-Prado MT, Hines JA, Vecchio KS. Acta Mater 2001;49:2905.

[101] Nesterenko VF, Meyers MA, Lasalvia JC, Bondar MP, Chen Y-J, Lukyanov YL. Mater Sci Eng A 1997;229:23.

[102] Guo YZ, Li YL, Pan Z, Zhou FH, Wei Q. Mech Mater 2010;42:1020. 